\title{
Design and Development of Mini Portable Cooler for Breastmilk Storage
}

\author{
Norhazwani Abd Malek ${ }^{1}$, Siti Zulaika Osman ${ }^{2}$, Nurhusna Mohamad Ehsan ${ }^{3}$, Nurzanariah Roslan ${ }^{4}$, Mohd Fakhri \\ Rosli $^{5}$ \\ ${ }^{1,3,4}$ College of Engineering, Universiti Tenaga Nasional \\ ${ }^{2}$ PGEO Edible Oils Sdn Bhd \\ ${ }^{5}$ Nichicon (M) Sdn Bhd \\ *Corresponding author E-mail: norhazwani@uniten.edu.my
}

\begin{abstract}
This paper presents the design and development of a mini portable cooler that utilizes the Peltier effect to cool the human expressed breast milk (EBM) within 24 hours at the temperature range between $4^{\circ} \mathrm{C}-15^{\circ} \mathrm{C}$ to maintain the high quality of the EBM for use at a later date and the health of the baby who consume it. It is developed to overcome the tediousness of using cooler bag/box, which requires ice packs that need repetitive freezing. A few prototypes with different sizes and body materials, namely polystyrene, polypropylene and aluminium, were successfully developed and tested to get the minimum temperature using $5 \mathrm{~V}$ power supply. In all graphs, the temperature is decreasing with time. The smallest size of the cooled space $(18 \mathrm{~cm}$ of width, $12 \mathrm{~cm}$ of length and $14 \mathrm{~cm}$ of height) has the lowest temperature compared to the other sizes for each body material. However, the lowest temperature of all body materials is obtained from aluminium with $11.2^{\circ} \mathrm{C}$ at 100 minutes. It also reaches below $15^{\circ} \mathrm{C}$ the fastest which is at 80 minutes compared to the other prototypes that need longer time. All in all, aluminium is the best body material for the mini portable cooler developed in this project.
\end{abstract}

Keywords: Breastmilk storage; Mini cooler; Peltier, EBM

\section{Introduction}

Awareness regarding breastfeeding has increased all over the world each year due to the fact that breastfeeding has many health benefits to the babies and their mothers for the short and longer terms. There is an increasing number of studies that report on associations between breastfeeding and long-term protection against chronic diseases [1]. It is a necessity for breastfeeding mothers who are going back to work or looking for more flexibility, to use breast pump. Once the EBM is collected, it is important for them to know how to safely store it. By following recommended storage, the safety and quality of the EBM can be maintained for the health of the baby. The temperature of EBM must be kept within a suitable range so that the nutrients will not be depleted. The EBM can be stored in the freezer, refrigerator, insulated bag with ice packs, or at room temperature for different time duration. The proper temperature to store EBM at different temperature found in the literature is shown in Table 1.

This paper presents the design and development of a working mini portable cooler that utilizes the Peltier effect to cool and store the EBM within 24 hours. This new invention is developed to overcome the tediousness of using cooler bag and cooler box as shown in Fig. 1, which requires ice packs that need repetitive freezing, and yet reducing the dependency on conventional refrigerator.

Peltier effect can be found from thermoelectric cooler (TEC) where it creates a temperature difference by transferring heat between two electrical junctions. When the current flows through the junctions of the two conductors, heat is removed at one junction and cooling occurs. Peltier coolers are accurate, easy to control and easy to adjust even though it not as efficient as some other cooling devices. Ideally, the amount of heat absorbed at the cold end and the heat dissipated at the hot end are dependent on the product of the Peltier coefficient and the current flowing through the semiconductor material. Due to the temperature difference between the cold and hot ends of the semiconductor material, heat will be conducted through the semiconductor material from the hot to cold end. As the current is increased, the temperature difference and the conducted heat increases too, because the Peltier cooling effect is increased. Fig. 2 below shows the configuration of the Peltier thermoelectric cooler.

Table 1: The proper temperature to store the EBM [2][3]

\begin{tabular}{|c|c|}
\hline Table 1: The proper temperature to store the EBM [2][3] \\
\hline Location & $\begin{array}{c}\text { Storage duration for freshly } \\
\text { EBM* }\end{array}$ \\
\hline $\begin{array}{c}\text { Deep freeze } \\
\left(0{ }^{\circ} \mathrm{F} /-18^{\circ} \mathrm{C}\right)\end{array}$ & 12 months \\
\hline $\begin{array}{c}\text { Refrigerator freezer } \\
\left(\text { variable } 0{ }^{\circ} \mathrm{F} /-18^{\circ} \mathrm{C}\right)\end{array}$ & $3-4$ months \\
\hline $\begin{array}{c}\text { Refrigerator } \\
\left(39^{\circ} \mathrm{F} / 4{ }^{\circ} \mathrm{C}\right)\end{array}$ & 8 days \\
\hline $\begin{array}{c}\text { Cooler with frozen ice packs } \\
\left(59^{\circ} \mathrm{F} / 15^{\circ} \mathrm{C}\right)\end{array}$ & 24 hours \\
\hline $\begin{array}{c}\text { Room temperature } \\
\left(66^{\circ} \mathrm{F}-72^{\circ} \mathrm{F} / 19^{\circ} \mathrm{C}-22^{\circ} \mathrm{C}\right)\end{array}$ & $6-10$ hours \\
\hline $\begin{array}{c}\text { Room temperature } \\
\left(72{ }^{\circ} \mathrm{F}-79^{\circ} \mathrm{F} / 22^{\circ} \mathrm{C}-26^{\circ} \mathrm{C}\right)\end{array}$ & 4 hours \\
\hline
\end{tabular}

*Storage duration may vary for preterm or sick babies. 


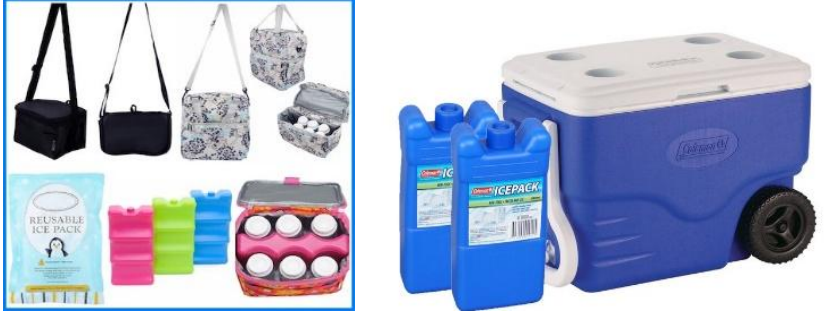

Fig. 1: Tediousness of using ice packs in cooler box/cooler bags

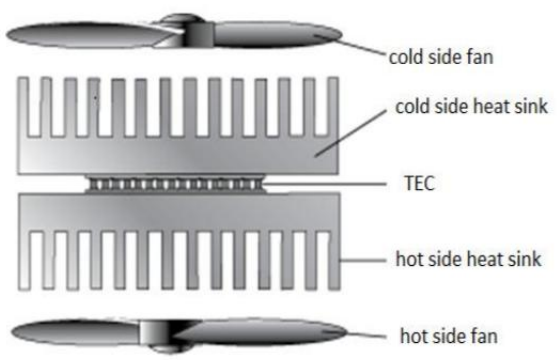

Fig. 2: the configuration of the Peltier thermoelectric cooler. [4]

\section{Literature Review}

Quite a number of research on thermoelectric cooler had been done by other researchers. One of them was Huang et al. [5] who did research on the design method of thermoelectric cooler using $12 \mathrm{~V}$ and $4.1 \mathrm{~A}$ to determine the physical properties and derive an empirical relation for the performance of thermoelectric module. Besides that, an experiment was carried out by Bansal et al [6] and Chien et al. [7] to investigate the behavior of thermoelectric chiller driven by solar cells. However, Chien et al. used nitrogen $\left(\mathrm{NH}_{3-}\right.$ $\mathrm{H}_{2} \mathrm{O}$ ) on their refrigeration system, which consumed a large amount of electricity and took a long time to achieve a stable temperature while its COP was only 0.25 .

Based on the existing thermoelectric mini coolers in the market nowadays, most of them are used to cool beverages, food and fruits. The design is also bulky and heavyweight, for instance Cooluli Mini Fridge Electric Cooler and Warmer [8] that can fit 4 litre at once and can maintain capacity temperature of $8^{\circ} \mathrm{C}$ below ambient and $62^{\circ} \mathrm{C}$ for cooling and warming respectively. Same goes with PsmGoods One Mini Fridge [9] and Neon ${ }^{\circledR}$ Portable USB Powered Mini Fridge [10] that can operate cooling and warming using switch. These two products can be operated at $5 \mathrm{~V}$ voltage and maximum power consumption of $10 \mathrm{~W}$ and the temperature range is between $8^{\circ} \mathrm{C}$ to $9^{\circ} \mathrm{C}$ for cooling and $40^{\circ} \mathrm{C}$ to $65^{\circ} \mathrm{C}$ for heating. Fig. $3-5$ show the existing coolers in market.

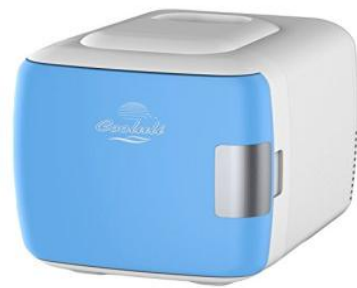

Fig. 3: Cooluli Mini Fridge Electric Cooler and Warmer [8]

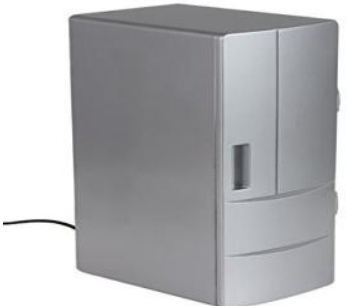

Fig. 4: PsmGoods One Mini Fridge [9]

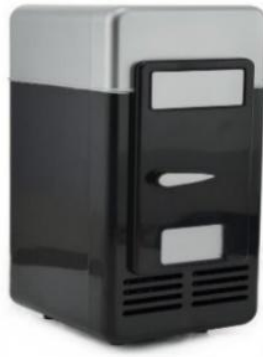

Fig. 5: Neon ${ }^{\circledR}$ Portable USB Powered Mini Fridge [10]

It is anticipated that the new invention developed in this project to be different from other products in the market. The design is expected to be small, lightweight and easy to carry in accordance to its purpose to cool human expressed breastmilk which normally will be used by working mothers.

\section{Methodology}

The project is divided into 3 stages which are the design of the cooler body and its circuit, fabrication and testing of the prototype. The data on the temperature in the mini cooler are obtained and compared, while the coefficient of performance is calculated.

\subsection{Design}

The body of the mini cooler is designed using 3D CAD software, CREO Parametric. The size of the mini cooler will be described in the next section. Fig. 6 below shows the body geometry designed in CREO Parametric.

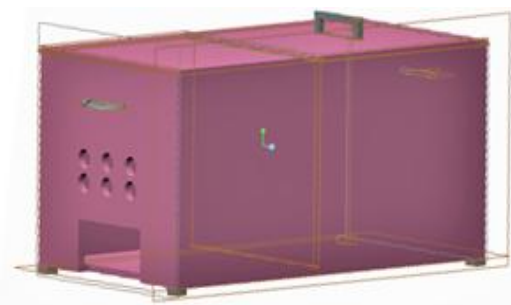

Fig. 6: The body geometry of portable cooler body designed in CREO Parametric software

The circuit components consist of thermoelectric module (TEC12706), heatsink, fan, 5V Universal Serial Bus (USB), Arduino Uno R3, temperature sensor, relay module and anymeter, as shown in Fig. 7.

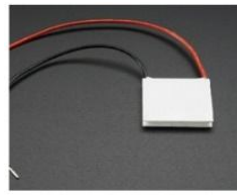

Thermoelectric module

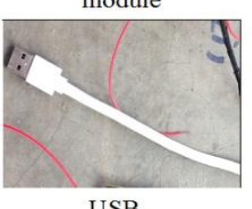

USB

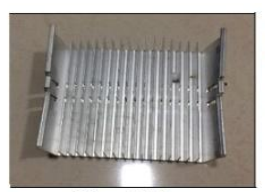

Heatsink

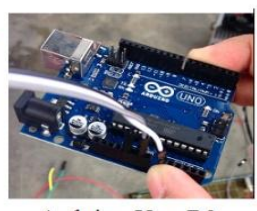

Arduino Uno R3

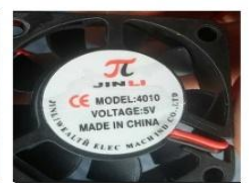

Fan

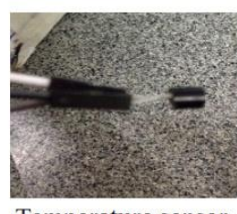

Temperature sensor

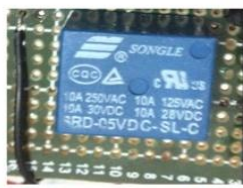

Relay Module

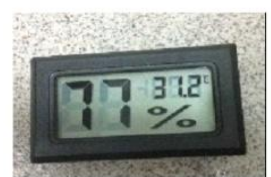

Anymeter

Fig. 7: The circuit components 


\subsection{Fabrication}

Three different materials are used as the body material of the mini cooler. Prototype 1, Prototype 2 and Prototype 3 is made of polystyrene, polypropylene and aluminium, respectively. All of them are shown in Fig. $8-10$.

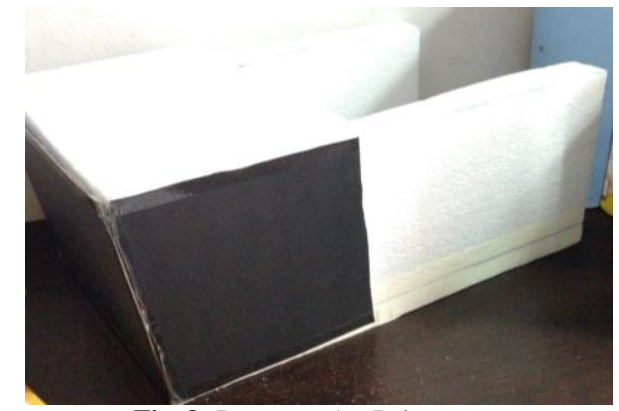

Fig. 8: Prototype 1 - Polystyrene

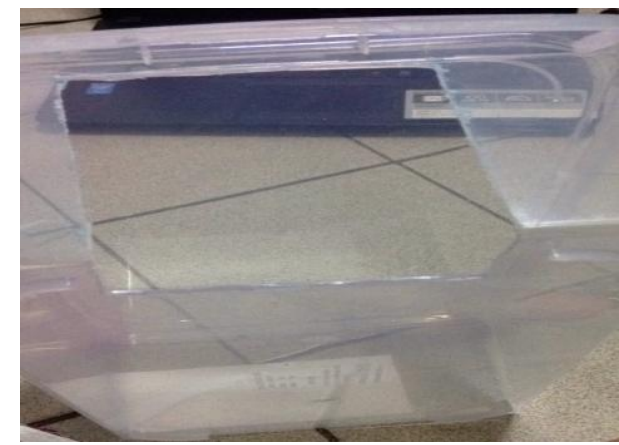

Fig. 9: Prototype 2 - Polypropylene

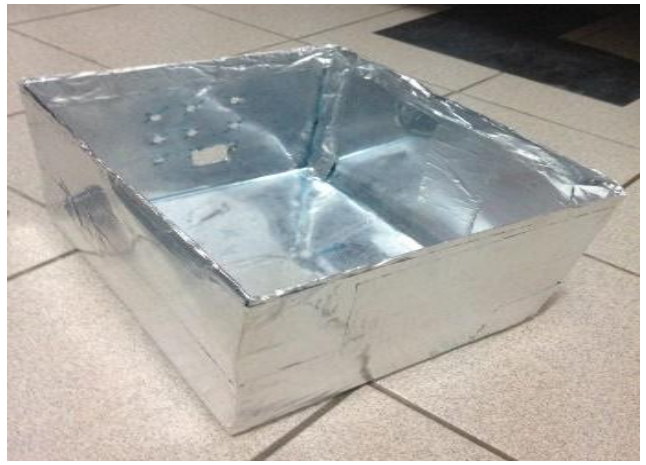

Fig. 10: Prototype 3 - Aluminium

\subsection{Testing and Calculation}

The prototypes are tested after the circuit components are attached to it, to ensure the temperature in the mini cooler is within the range of $4^{\circ} \mathrm{C}$ to $15^{\circ} \mathrm{C}$. These can be seen in Fig. $11-13$.

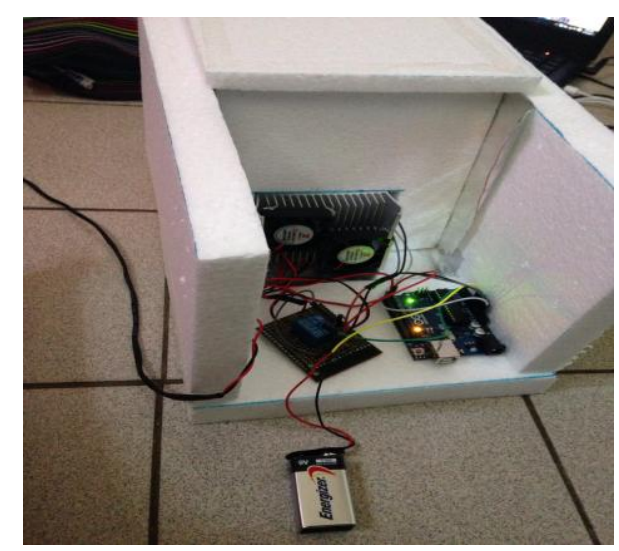

Fig. 11: Testing of Prototype 1

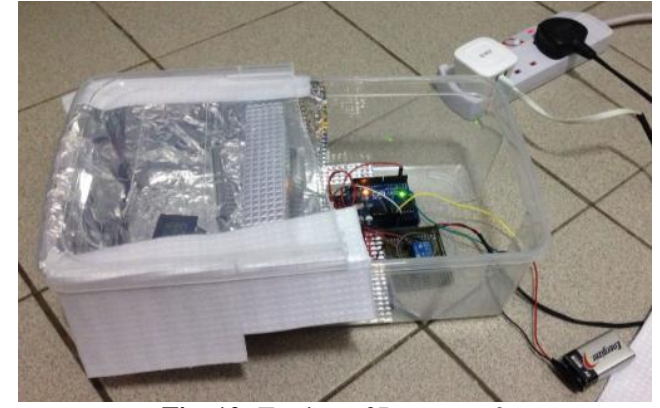

Fig. 12: Testing of Prototype 2

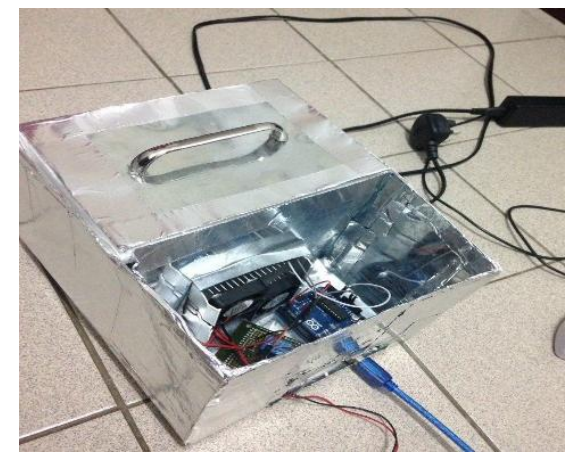

Fig. 13: Testing of Prototype 3

\section{Results and Discussions}

The temperature in the mini cooler is collected for every 10 minutes until 100 minutes. For each prototype, the length of the cooled space is varied while the height and width remain the same. The results of the testings can be seen in Fig. 14-16.

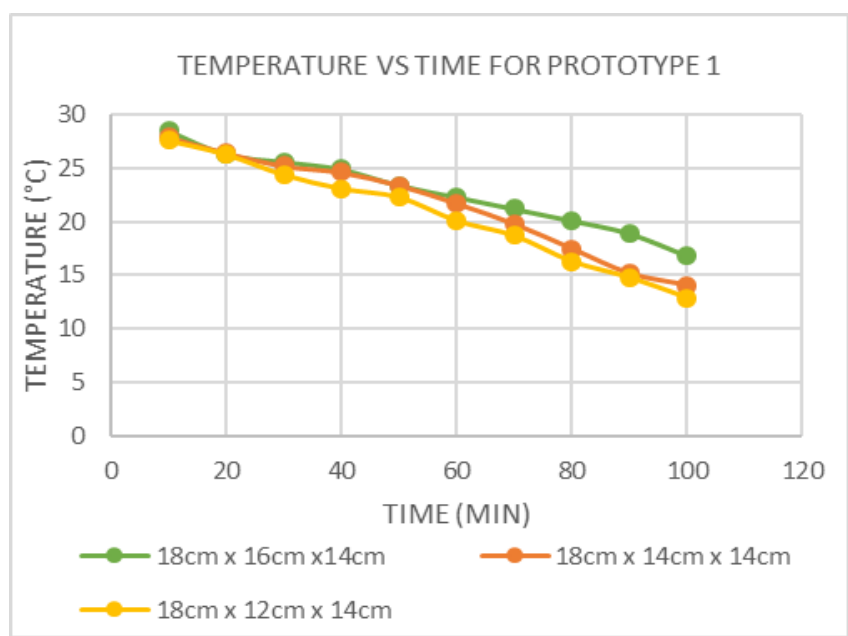

Fig. 14: Graph of Temperature vs. time for Prototype 1

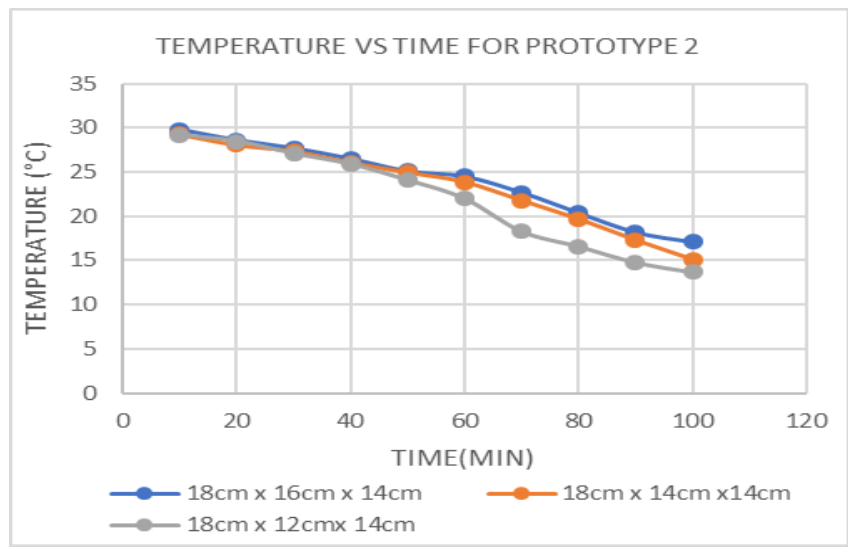

Fig. 15: Graph of Temperature vs. Time for Prototype 2 


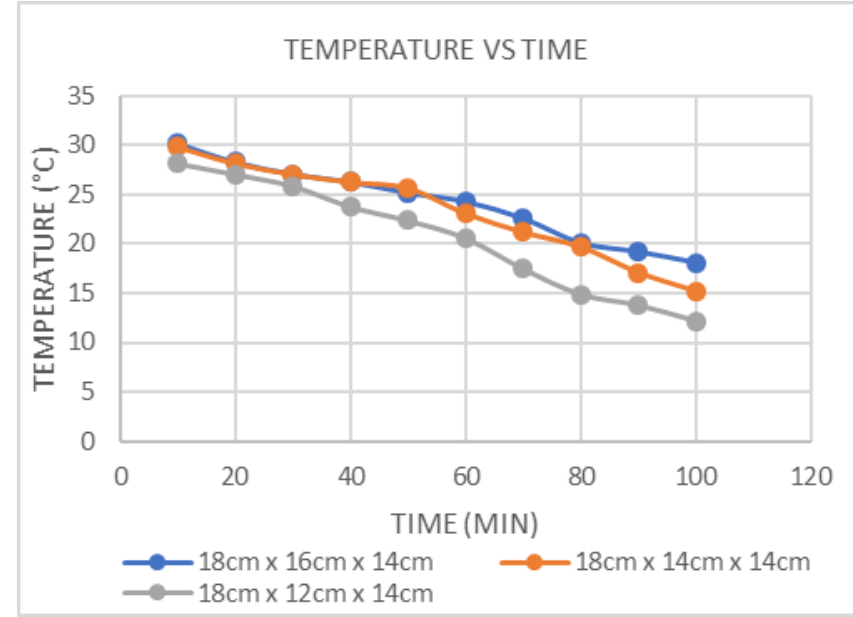

Fig. 16: Graph of Temperature vs. Time for Prototype 3

In all graphs, the trend is similar as the temperature is decreasing with time. The smallest size of the cooled space which is $18 \mathrm{~cm}$ of width, $12 \mathrm{~cm}$ of length and $14 \mathrm{~cm}$ of height has the lowest temperature compared to the other sizes for each prototype. However, the lowest temperature of all prototypes is obtained from Prototype 3 with $11.2^{\circ} \mathrm{C}$ at 100 minutes. It also reaches below $15^{\circ} \mathrm{C}$ the fastest which is at 80 minutes compared to the other prototypes that need longer time. The temperatures obtained from the testing using the smallest size of each prototype are tabulated in Table 2 .

Table 2: The temperatures obtained from the testing using the smallest size of each prototype

\begin{tabular}{|c|c|c|c|}
\hline \multirow{2}{*}{$\begin{array}{c}\text { Time } \\
(\text { min) }\end{array}$} & $\begin{array}{c}\text { Porotype 1 } \\
\text { (polystyrene) }\end{array}$ & $\begin{array}{c}\text { Porotype 2 } \\
\text { (polypropylene) }\end{array}$ & $\begin{array}{c}\text { Porotype 3 } \\
\text { (aluminium) }\end{array}$ \\
\hline 10 & 27.6 & 29.2 & 26.2 \\
\hline 20 & 26.3 & 28.5 & 27.1 \\
\hline 30 & 24.4 & 27.1 & 25.9 \\
\hline 40 & 23.1 & 25.9 & 23.8 \\
\hline 50 & 22.3 & 24.1 & 22.4 \\
\hline 60 & 20.1 & 22.0 & 20.6 \\
\hline 70 & 18.7 & 18.3 & 17.5 \\
\hline 80 & 16.3 & 16.6 & 14.9 \\
\hline 90 & 14.8 & 14.8 & 13.8 \\
\hline 100 & 13.9 & 13.7 & 11.2 \\
\hline
\end{tabular}

From Table 2 it can be observed that aluminium is the best material for the body of this mini cooler compared to other prototypes. After 80 minutes, the temperature in the mini cooler has reached the desired temperature which is between $4^{\circ} \mathrm{C}$ to $15^{\circ} \mathrm{C}$, in which the time is longer for the other prototypes. This temperature range is suitable to store the EBM in 24 hours without spoiling it. In addition to that, aluminium used has the thickness of $2 \mathrm{~mm}$ and is considered lightweight. Aluminium is also not easily damaged compared to polystyrene and better thermal conductivity compared to other prototype materials.

Based on individual components prices of Prototype 3, the total price is approximately RM 150 (around 37 USD with the current exchange rate). This price is affordable as it is in the same price range to the price of the cooler box or insulated bag with ice packs that are commonly used to store the EBM. Even though cooler bags and ice packs price is within RM 100 to RM 200, it is quite tedious to use as the ice packs need to be cooled before use.

\section{Conclusion}

A mini portable cooler to cool human EBM in the temperature range between $4^{\circ} \mathrm{C}$ to $15^{\circ} \mathrm{C}$ has been designed and the prototypes have been developed with three different body materials. This small, lightweight and portable cooler is using $5 \mathrm{~V}$ power supply.
It can be used to replace the use of cooler bag and cooler box that needs ice packs to cool it, hence reducing the tediousness of using ice packs as it requires repetitive freezing. Among the materials used in the testings, aluminium is selected as the best body material for this mini cooler as the temperature in it reaches the desired temperature range faster compared to polystyrene and polypropylene. However, even though the desired temperature range is reached, but the time taken to reach this is considered long. It is recommended that a further research to be done using $12 \mathrm{~V}$ power supply and more insulation materials to be added in the mini cooler to reduce the temperature and also time taken to reach the desired temperature.

\section{Acknowledgement}

The authors would like to thank Universiti Tenaga Nasional for its financial support through the internal project grant (J510050756).

\section{References}

[1] Colin Binns, MiKyung Lee, Wah Yun Low,"The Long-Term Public Health Benefits of Breastfeeding", Asia Pasific Journal of Public Health, Vol.28, No.1, (2016), pp.7-14.

[2] Jones, F., "Best Practice for Expressing, Storing and Handling Human Milk in Hospitals, Homes and Child Care Settings", Raleigh, NC: Human Milk Banking Association of North America, 2011;

[3] Mohrbacher, N., "Breastfeeding Answers Made Simple: A Guide for Helping Mothers", Amarillo, TX: Hale Publishing, 2010.

[4] B. J. Huang, C. J. Chin and C. L. Duang, " Improvement in the COP of Thermoelectric Cooler," International Journal of Scientific \& Technology Research, Vol. 5, Issues 05, (2016), ISSN 2277 8616.

[5] B. J. Huang, C. J. Chin and C. L. Duang, "A design method of thermoelectric cooler," International Journal of Refrigeration, Vol. 23, (2000), pp. 208-218.

[6] P. K. Bansal and A. Martin, "Comparative study of vapour compression, thermoelectric and absorption refrigerators," International Journal Energy Research, Vol. 24, (2000) pp. 93-107.

[7] Z.-J. Chien, H.-P. Cho, C.-S. Jwo, C.-C. Chien, S.-L. Chen and Y.L. Chen, "Experimental Investigation on an Absorption Refrigerator Driven by Solar Cells," International Journal of Photoenergy, (2013), pp. 1-6.

[8] "Cooluli Mini Fridge Electric Cooler and Warmer (4 Liter / 6 Can) AC/DC Portable," Cooluli, [Online]. Available: https://www.amazon.com/Cooluli-Fridge-Electric-CoolerWarmer/dp/B01G7IL3BS/ref=cm_cr_arp_d_product_top?ie=UTF8 . [Accessed 2017].

[9] "PsmGoods Set Cooling And Heating Functions As One Mini USB Powered Fridge For Beverage Drink Cans in Cubicle/Car and Home office Which Can Be Placed Within Two Drinks," [Online]. Available: https://www.amazon.in/PsmGoods-Cooling-HeatingFunctions-Beverage/dp/B00QUW4O90. [Accessed 4 February 2017].

[10] "Neon® Portable USB Powered Mini Fridge Cooler and Warmer Can Refrigerator for Beverage, Drink, Beer - Plug and Play," [Online]. Available: https://www.amazon.com/Portable-PoweredFridge-Refrigerator-Beverage/dp/B00UYRNO9I. [Accessed 3 January 2017].

[11] E. C. Boelman, B. B. Saha and T. Kashiwagi, "Experimental investigation of a silica gel-water adsorption refrigeration cycle -The influence of operating conditions on cooling output and COP," United States: American Society of Heating, Refrigerating and AirConditioning Engineers, Inc., Atlanta, GA (United States)., 1995.

[12] K. O. U. Elsevier Science Ltd., "Thermoelectric materials: principles, structure, properties, and applications. Encyclopedia of materials: science and technology," pp. 1-11.

[13] S. Banjerd and N. Afzulpurkar, "A Novel Approach for Cooling Electronics Using a Combined Heat Pipe and Thermoelectric Module," American J. of Engineering and Applied Sciences, Vol. 2, No. 4, (2009), pp. 603-610. 